\title{
Formate Assisted Pyrolysis of Pine Sawdust for in-situ Oxygen Removal and Stabilization of Bio-oil
}

\author{
Paige A. Case ${ }^{\mathrm{a}}$, M. Clayton Wheeler ${ }^{\mathrm{a}, \mathrm{b}}$ and William J. DeSisto ${ }^{\mathrm{a}, \mathrm{b}_{*}}$
}

a. Department of Chemical and Biological Engineering, University of Maine, Orono, ME 04469

b. Forest Bioproducts Research Institute, University of Maine, Orono, ME 04469

\begin{abstract}
Pine sawdust was pretreated with several calcium compounds and then pyrolyzed in a fluidized bed pyrolysis reactor at $500{ }^{\circ} \mathrm{C}$. The catalytic action of the calcium compounds varies depending on the anion. Analysis of pyrolysis gas, liquid and char yields and compositions demonstrates that calcium sulfate is inert during pyrolysis while calcium formate, carbonate, hydroxide and oxide show significant deoxygenation activity. Of the salts which showed deoxygenation activity, calcium formate had the highest relative yield. This effect is likely attributable to the activity of calcium formate as a hydrogen donor at the pyrolysis temperature.

*Corresponding author
\end{abstract}




\section{Introduction}

Commercial production of renewable transportation fuels and chemicals from lignocellulosic biomass is hindered by both high capital and operating costs. The capital cost stems from small processing scales (relative to petrochemical) which are limited by the high biomass transportation costs. The operating costs reflect the natural resistance of woody biomass to decomposition, and the cost of removing oxygen while maintaining an economical product yield. Biomass pyrolysis has been identified as a process which can overcome the capital cost barrier, but the upgrading of the resulting bio-oil is still difficult and costly because the complex chemical and oxygenated nature of the oil requires a number of reactors, catalysts and significant amounts of hydrogen, while the product yield is relatively low (Hicks, 2011; Kakzeski et al., 2010; Wildschut et al., 2009). To date, the development of catalysts for post-treating bio-oil have been challenged by high coke/char yields and deactivation, due to the highly reactive nature of bio-oil (Mortensen et al., 2011; Zacher et al., 2014).

To reduce the burden of hydrotreating bio-oil from pyrolysis, methods such as catalytic pyrolysis have been demonstrated (Agblevor et al., 2010; Mihalcik et al., 2011). In catalytic pyrolysis, a zeolite catalyst is used during fast pyrolysis to promote cracking reactions that increase the $\mathrm{C} / \mathrm{O}$ ratio and aromatics concentration (Carlson et al., 2011). Oxygen is removed as $\mathrm{CO}_{2}$ which reduces the carbon yield, yet does not require external hydrogen. While improvements in bio-oil quality have been reported, challenges such as process yields, catalyst regeneration and catalyst attrition remain. The composition of biomass limits mass yields because of the low $\mathrm{H}: \mathrm{C}$ ratio of the starting material and the 
tendency of carbohydrates to undergo dehydration and condensation (coke forming) reactions. The use of hydrogen as a carrier gas during catalytic pyrolysis (catalytic hydropyrolysis) has been shown to improve both the quality and yield of bio-oil by removing oxygen from the biomass as water, increasing the carbon yield in the liquid (Marker et al., 2012; Meesuk et al., 2011; Venkatakrishnan et al., 2014).

As an alternative to zeolite-based catalytic pyrolysis, the effects of alkaline earth metal compounds on biomass pyrolysis have been explored by several groups. Wang, et al. mixed calcium hydroxide physically with pine at weight loadings up to $22 \%$ (Wang et $a l ., 2010)$. The authors found that the addition of the alkaline earth base slightly increased the overall yield while inhibiting the formation of acids, reducing the amount of sugars formed and increasing ketone and alcohol yields. Work by Lin, et al. mixing calcium oxide with loadings of 100-500\% on pine also showed an increase in bio-oil yield accompanied by a decrease in oxygen content from 39 to $31 \mathrm{wt} \%$ at the highest loading (Lin et al., 2010). Another recent study by Veses and coworkers demonstrated deoxygenation and decrease in acidity of bio-oil when calcium oxide and magnesium oxide were used as catalysts in an auger reactor (Veses et al., 2014). Pyrolysis of magnesium oxide loaded cotton seed was studied by Pütün. The addition of oxide decreased the oxygen content by $50 \%$, but unlike the calcium studies, bio-oil yield decreased with the addition of the alklaine earth metal (Pütün, 2010). The differing results between these studies illustrate the effect of reactor design and feedstock choice, as well as the pre-treatment process. 
Recently, a simple and robust modification to the pyrolysis process was reported, which has the potential to reduce the complexity of upgrading the oil and increases process yields compared to catalytic fast pyrolysis. The process, called formate-assisted fast pyrolysis or FAsP, has been demonstrated on lignin (Mukkamala et al., 2012). By pretreating the feedstock with calcium formate, a significantly deoxygenated bio-oil is produced in a single-step, atmospheric fast pyrolysis process.

In the current work, FAsP of pine (pinus strobus) sawdust was compared to conventional pyrolysis and several other calcium pretreatments. For all of the calcium pretreatments (with the exception of calcium sulfate), the oil quality was superior to conventional pine pyrolysis oil, having a significantly lower oxygen content, lower degree of polymerization and increased stability. Because the oil was less oxygenated, less hydrogen would be required for upgrading, thereby reducing the cost and complexity of downstream processing.

\section{Materials and Methods}

\subsection{Feedstock Preparation}

The calcium compounds were incorporated with the pine sawdust by forming a solution/suspension with the salt in deionized water, and then incorporating the dry sawdust. The mass loading of calcium was maintained constant for all experiments at $0.43 \mathrm{~g}$ calcium/g sawdust. This loading corresponds to the addition of $146 \mathrm{~g}$ calcium sulfate, $140 \mathrm{~g}$ calcium formate, $107 \mathrm{~g}$ calcium carbonate, $79 \mathrm{~g}$ calcium hydroxide and 60 g calcium oxide, respectively, each to $100 \mathrm{~g}$ pine sawdust. In all cases, the pretreated 
pine was oven dried to 5-10\% moisture and sieved to achieve particles smaller than 1.5 $\mathrm{mm}$.

\subsection{Pyrolysis}

The pretreated sawdust was pyrolyzed with 40-60 mesh sand as heat transfer medium in a $3.5 \mathrm{~cm} \times 30 \mathrm{~cm}$ entrained flow reactor described in detail elsewhere (DeSisto et al., 2010). The reactor temperature was measured using two K-type thermocouples located on the vertical axis measured 3.0 and $9.5 \mathrm{in}$. from the top of the reactor. The pine/calcium formate mixture was metered through a screw feeder and pneumatically fed into the reactor, using a nitrogen flow rate of $6 \mathrm{~L} / \mathrm{min}$. The feed rate of the pretreated pine was approximately $1 \mathrm{~g} / \mathrm{min}$, and up to $1 \mathrm{~kg}$ of material could be processed in a run. The pyrolysis temperature was $500{ }^{\circ} \mathrm{C}$. Immediately downstream of the reactor, char was separated using a hot gas filter (HGF) also maintained at $500{ }^{\circ} \mathrm{C}$. The total vapor residence time in the fluidized bed reactor and the HGF was $12 \mathrm{sec}$, with about $90 \%$ of that time in the HGF. After the vapor passed through the hot gas filter the liquid was collected in a condenser operated at $6{ }^{\circ} \mathrm{C}$, followed by an electrostatic precipitator (ESP) to collect aerosols. The gas exhaust from the ESP was periodically sampled and analyzed by GC. The exhaust gas flow rate was measured using a dry gas meter. Liquid yield was determined by weighing the condenser and electrostatic precipitator before and after pyrolysis. The char yield was determined by weighing the material collected in the reactor and the char filter, and then subtracting the mass of calcium compounds). The gas yield was measured using a dry gas meter. Each of the experiments was performed in duplicate, at minimum. 


\subsection{Characterization}

\subsubsection{Bio-Oil Characterization}

The bio-oil analyses were conducted on oils collected from the electrostatic precipitator to ensure a water-free sample, as water can affect the results obtained from elemental analysis and size exclusion chromatography.

\subsubsection{Elemental Analysis}

Carbon, hydrogen and nitrogen analysis of the oil from the electrostatic precipitator was performed using a Thermo Scientific Flash 2000 elemental analyzer, and oxygen was calculated by subtracting the carbon, hydrogen and nitrogen from the total mass. This calculation has previously been compared to measured oxygen content using the same elemental analyzer and the difference method was found to be accurate for calculation of oxygen content for ash-free or low-ash samples.

\subsubsection{Size Exclusion Chromatography}

Size exclusion chromatography (SEC) was performed using an Shimadzu HPLC-GPC equipped with two columns measuring 1-1k Daltons and 1k-20k Daltons, respectively, with N,N-dimethylformamide (DMF) as the mobile phase. Due to the relatively low molecular weight of the oils produced with hot gas filtration, a large fraction of the sample elutes at the end of the calibration range with low resolution, making it difficult to quantitatively determine the molecular weight distribution and average molecular weight. Therefore, results from this method were used for comparative purposes only. 


\subsubsection{Quantitative Analysis by GC/MS}

A Shimadzu Q2010 gas chromatograph-mass spectrometer (GC-MS) was used to characterize the composition of the oils. The samples were diluted with ethyl acetate solvent and prepared by adding butylated hydroxytoluene as a recovery standard and biphenyl as an internal standard. All of the samples were derivatized with N-Methyl-N(trimethylsilyl) trifluoroacetamide (MSTFA) for one hour before analysis. Compounds reported were verified by both mass spectral fragmentation pattern and retention time matches to genuine standards.

\subsubsection{Char Characterization}

The solid product (containing char and inorganic compounds from the various calcium pretreatments) was analyzed by thermogravimetric analysis using a TA instruments Q500 TGA with a heating rate of $10^{\circ} \mathrm{C} / \mathrm{min}$ in a nitrogen environment.

\subsubsection{Gas Characterization}

The pyrolysis exhaust gas was measured using an SRI 8610C portable GC calibrated with a certified mixture of $1 \%$ methane, ethane, ethylene, acetylene, carbon monoxide and carbon dioxide in nitrogen.

\section{Results and Discussion}

\subsection{Effect of Calcium Pretreatment on Pyrolysis Yields}

The solid, liquid and gas yields, based on the starting pine sawdust mass, for each of the pretreated pine samples are shown in Table 1 . The liquid yield represents the mass 
collected in the condenser and electrostatic precipitator. The liquid was comprised of an organic fraction and aqueous fraction in the condenser, with only the organic fraction present in the ESP. The organic fraction was slightly denser and phase separated from the aqueous fraction.

A significant amount of gas was produced for all of the experiments, including from untreated pine sawdust. Previous work has shown that the presence of the hot gas filter results in more gas-forming reactions (Case et al., 2014). The gas yield is lower for the calcium sulfate pretreated sawdust, than for the untreated pine which corresponds with the higher liquid yield observed for that pretreatment.

\subsection{Effect of Calcium Pretreatment on Gas Composition}

Calcium formate was used as a pretreatment compound because of its action as a hydrogen donor upon heating, When calcium formate is pyrolyzed at temperatures greater than about $450{ }^{\circ} \mathrm{C}$, the formate salt decomposes to produce solid calcium carbonate and gaseous carbon monoxide and hydrogen.

If calcium formate simply decomposed without molecular interaction with pyrolysis intermediates, an overall gas yield of approximately $90 \mathrm{~g} / \mathrm{g}$ pine would be expected, with about $52 \mathrm{~g} \mathrm{CO} / \mathrm{g}$ pine. However, the gas yield for calcium formate pretreated pine is only slightly higher than that of untreated pine, 59 vs. $57 \mathrm{~g} / \mathrm{g}$ pine as shown in Figure 2 . This comparison, as well as the increased organic yield observed with calcium formate pretreatment (Table 1), indicates that some fraction of both the hydrogen and carbon 
being produced during calcium formate decomposition are being incorporated into the liquid pyrolysis product.

Calcium hydroxide and calcium oxide have a significantly lower gas yield when compared to untreated pine. Calcium hydroxide dehydrates to form calcium oxide, and with $\mathrm{CO}_{2}$ present, the oxide likely sequesters some gaseous $\mathrm{CO}_{2}$ in the solid product as carbonate. This hypothesis is supported by the specific decrease in $\mathrm{CO}_{2}$ observed with these pretreatments. In contrast, the gas yield for the calcium carbonate pretreated pine is similar to that of untreated pine. This is not surprising considering the calcium exists as a carbonate both before and after the reaction, although its chemical nature during the reaction is not known since there is an observable effect on the pyrolysis oil composition.

\subsection{Effect of Calcium Pretreatment on the Physical and Chemical Properties of Bio-oil}

\subsubsection{Elemental Analysis}

The carbon, hydrogen and oxygen content, which are important for fuel quality, were determined for all of the organic liquids, and the results are presented in Table 2.

A significant decrease in O:C ratio results from pre-treatment with all of the calcium compounds except for calcium sulfate. The calcium sulfate increases the overall oxygen content and $\mathrm{O}: \mathrm{C}$ ratio compared to untreated pine. For each of the other pretreatments, the oxygen content is decreased between $35-60 \%$. For calcium formate pretreatment, no reduction in $\mathrm{H}: \mathrm{C}$ ratio is observed, likely due to incorporation of formate-derived hydrogen, while pretreatment with carbonate, hydroxide and oxide cause a small 
decrease. The carbon yield is increased for calcium formate pretreatment, compared to pyrolysis of untreated pine, indicating that carbon from the calcium formate may also be incorporated into the liquid product.

\subsubsection{Chemical Composition from Quantitative GC/MS}

The organic fractions of the oil products were analyzed by GC/MS. In each case, between $10-20 \%$ of the total oil was identified. This was limited because GC/MS is only able to detect compounds which have a minimum volatility, and preparing standards for each of the hundreds of detectable compounds is not practical or economically feasible since many are not available commercially. Trimethylsilyl (TMS) derivitization helps to improve the number of detectable compounds by increasing the volatility of hydroxylated compounds. Even so, high molecular weight compounds like polyaromatic hydrocarbons (PAH) and long-chain fatty acids are unaffected. Many low-molecular-weight acids and aldehydes are not quantifiable because of overlap with the solvent and MSTFA decomposition product peaks. Table 3 lists the most significant compounds identified by GC/MS. The percentage of the oil that can be quantified increases with calcium pretreatment, likely because more of the compounds are lower molecular weight phenolics. The exception to this is the untreated pine oil, which contains a large amount of levoglucosan, the cellulose anhydrosugar, which is quantifiable in GC/MS after derivitization.

Figure 3a presents the concentrations of major phenolic compounds identified by GC/MS. Major peaks include catechols, phenols and alkyl substituted catechols and 
phenols. There is a shift from catechol-type compounds to phenol-type compounds when pyrolyzing calcium formate, carbonate, hydroxide or oxide pretreated pine. Additionally, these pretreatments also lead to increased alkylation of the phenolic compounds, increasing the relative concentrations of methyl-, C2- and C3- alkyl substituted phenols. The presence of alkylated phenols is consistent with the products of lignin FAsP where methoxy-phenols were observed to convert to alkylated phenols during oxygen removal (Mukkamala et al., 2012). Additionally, cellulose has been shown to form phenolics under pyrolysis conditions (Byrne et al., 1966), therefore some of the phenolics in the oil may originate from the carbohydrate fraction of the pine.

Five-membered rings such as furfural and 5-hydroxymethyl furfural (5-HMF) are common decomposition products of the hemicellulose fractions of biomass. When pretreatment with calcium formate, carbonate, hydroxide or oxide is applied, however, the furfural disappears and the concentration of substituted cyclopentenones significantly increases (Figure 3b). These results are consistent with the literature, which has shown that alkali compounds catalyze formation of substituted cyclopentenones (Di Blasi et al., 2009). The source of these compounds has been hypothesized to be carbohydrates, however the same compounds were observed during FAsP of lignin, indicating that these compounds may be alkali catalyzed decomposition products of lignin monomers or linkages.

Another significant effect of calcium pretreatment is the decrease in anhydrosugars such as levoglucosan. This result is supported by literature, which has shown that alkali and 
alkaline earth metals promote gas forming reactions over depolymerization and dehydration (Patwardhan et al., 2010).

Another interesting result from calcium treatment is the presence of retene (1-methyl-7isopropyl phenanthrene). Retene can be formed from dehydroabietic acid (one of the major resin acids found in pine). This transformation consists of decarboxylation, demethylation and dehydrogenation reactions and is not energetically favorable during conventional pyrolysis (Marchand-Geneste \& Carpy, 2003). Almost complete conversion of dehydroabietic acid to retene is observed when calcium is added, however. This may be due to the decarboxylation potential of calcium. Decarboxylation has a high energy barrier, but if it can be catalyzed by calcium, the rest of the conversion to retene may occur. This reaction liberates 4 moles of $\mathrm{H}_{2} /$ mole dehydroabietic acid, potentially providing a native, in-situ hydrogen source.

\subsubsection{Qualitative Stability Analysis by Size Exclusion Chromatography}

One of the most significant characteristics of oils obtained from pine pretreated with calcium formate, carbonate, hydroxide or oxide is their stability compared to conventional pine bio-oil. Figure 4 presents SEC data for each of the oils before, during and after aging. The improved stability of these oils is likely attributed to the chemical changes in the oil, specifically reduced low oxygen content, which is typically directly correlated with stability. In addition to the increased stability, a shift in molecular weight distribution to the lower molecular weight region (relative to untreated pine pyrolysis oil) occurs with all of the calcium pretreatments except for calcium sulfate. 


\subsection{Potential Mechanisms for the Catalytic Activity of Calcium Pretreatment}

During pyrolysis of mixtures of biomass/biomass constituents and alkali/alkaline earth metal salts many chemical and physical processes occur simultaneously. Depending on the salt used, different interactions will take place.

\subsubsection{Transformations of Calcium Pretreatment Compounds During Pyrolysis}

Calcium sulfate is very stable to extremely high temperatures, and does not appear to interact with the biomass at all. The increased mass yield and lower-quality oil produced from calcium sulfate pretreatment may have to do with the physical dilution of pine sawdust during pyrolysis, which may inhibit heat transfer and cracking reactions. Although calcium carbonate is also quite stable to temperatures higher than those used for pyrolysis, this pretreatment has a significant effect on both the yield and quality of the oil. While the mechanism for this effect is not fully understood, similar results have been observed in the literature (Di Blasi et al., 2009). Calcium hydroxide and calcium oxide both have the ability to sequester $\mathrm{CO}_{2}$ from the gas phase, thus producing a more reducing environment. As in the case with calcium carbonate, however, the action of the cation is not yet fully understood. One potential effect is the in-situ neutralization of acidic compounds such as formic and acetic acid, which are known to cause instability in conventional pyrolysis oils (Diebold, 2000). Decarboxylation of organic acids is also possible, and evidence for this pathway is shown during the transformation of dehydroabietic acid to retene. 


\subsubsection{Incorporation of carbon and hydrogen from calcium formate}

When calcium formate pretreated pine is pyrolyzed, the formate salt decomposes at approximately $450{ }^{\circ} \mathrm{C}$ to form carbonate, carbon monoxide and hydrogen (Mars et al., 1963). It is possible that this decomposition causes the hydrogen (possibly radicals) to be generated within, or in the vicinity of, the solid particles. The hydrogen and carbon monoxide at this high temperature further reacts with the pyrolyzing biomass to remove oxygen, in-situ. The incorporation of hydrogen and carbon from the calcium formate with the biomass provides deoxygenation of the liquid product without a decrease in overall liquid yield or $\mathrm{H}: \mathrm{C}$ ratio.

\subsubsection{Effect of calcium pretreatment on carbohydrates}

The lower liquid yields for pyrolysis of calcium pretreated pine relative to untreated pine correlate to decreased production of levoglucosan and other hemicelluloses derived anyhydrosugars and furans. These carbohydrate pyrolysis intermediates responsible are a significant mass fraction of conventional pyrolysis oil, with levoglucosan making up about $60 \%$ of the total product obtained from pyrolysis of pure cellulose (Patwardhan et al., 2010). Alkali and alkaline earth metals, however, have been found to promote pathways that favor cracking of cellulose to light oxygenates or formation of primary char (Kawamoto et al., 2008; Kuzhiyil et al., 2012). The elimination of anhydrosugars and furan compounds is not necessarily undesirable, however, as these compounds cause issues with downstream processing. They are highly oxygenated, include ring-bound oxygen and are very stable, making them poor 
candidates for hydrodeoxygenation. During catalytic upgrading, the fate of most carbon and hydrogen bound in these compounds is as gas or coke (Kaldstrom et al., 2011).

\subsection{Implications for process economics}

Pretreatment with inexpensive and recyclable compounds has the potential to transform present concepts of biomass conversion because it directly utilizes all biomass components (carbohydrates and lignin) for production of a stable, deoxygenated bio-oil with competitive yield in a single atmospheric fast pyrolysis step, which is compatible with the scale of biomass supply.

\subsubsection{Effect of calcium pretreatment on capital cost for pyrolysis}

This process generates oil with a similar yield and quality to that of catalytic fast pyrolysis, but has the potential to reduce the cost of pyrolysis because of the extremely low cost of calcium compounds. (Agblevor et al., 2010; Carlson et al., 2011; Mullen et al., 2011). This simplifies the design of the pyrolysis reactor and reduces the capital cost.

\subsubsection{Proposed process for calcium integration and recycle}

Calcium sulfate and calcium oxide can be recycled after the char is burned off. Calcium carbonate can be formed by passing exhaust gas over the calcined oxide, and calcium hydroxide can be formed by slaking the calcined oxide. Calcium formate can be generated from the byproducts of pyrolysis, as outlined in Figure 5. Use of calcium oxide as the heat transfer medium makes recycle possible, since separation of solids is extremely difficult. 


\subsubsection{Effect of calcium pretreatment on downstream upgrading processes}

Catalytic upgrading of pyrolysis oil is a necessary finishing step to produce a drop-in fuel. One obstacle to hydrodeoxygenation of bio-oil is its instability. Conventional bio-oil polymerizes over time and with increased temperature. Hydrotreating is generally

performed at temperatures between 150 and $300{ }^{\circ} \mathrm{C}$, at which bio-oil rapidly polymerizes. This leads to considerable char production and mass loss during upgrading. Oil produced by pyrolysis of calcium pretreated pine overcomes this issue by eliminating compounds that cause polymerization as well as compounds which do not contribute to the liquid product of upgrading. Hydrodeoxygenation of major compounds identified in the calcium pretreated pine oils has been proven in several studies (Wan et al., 2012; Zhao et al., 2011; Zhao et al., 2010).

\subsubsection{Comparison of calcium pretreatment processes}

The choice of calcium compound for pyrolysis pre-treatment in a commercial-scale operation would be guided by economics. More analysis of the capital investment required for regeneration of calcium formate is necessary. The end-use application of the pyrolysis oil is also an important factor in determining the type of upgrading required and the capital and operating costs associated with that stage.

\section{Conclusions}

Pretreatment of pine with various calcium compounds has a significant effect on the physical and chemical properties of pyrolysis oil, including dramatically lowering the oxygen content of the oil and increasing its stability. This improvement in oil quality is 
accomplished without external hydrogen or expensive catalysts in a single-step reactor, making it a simple, inexpensive and robust process. Additionally, the upgrading process burden is significantly reduced, lowering the cost required for fuel finishing. Among the calcium pretreatments employed, calcium oxide showed the highest percent deoxygenation in the liquid phase, while calcium formate showed significant deoxygenation without sacrificing bio-oil yield.

\section{Acknowledgements}

The authors would like to acknowledge Saikrishna Mukkamala, Jincy Joseph, Brian Frederick and Elizabeth Stemmler for their important contributions. The authors also acknowledge Matthew Rasmussen for his help with developing GC-MS techniques, Jamie St. Pierre for assistance with TGA experiments, and Nick Hill and Ken Hill for their technical assistance. This work was supported by the U.S. Department of Energy, Office of Science, Basic Energy Sciences, under Award \# DE-FG02-07ER46373. 


\section{References}

1. Agblevor, F.A., Beis, S., Mante, O., Abdoulmoumine, N. 2010. Fractional catalytic pyrolysis of hybrid poplar wood. Industrial \& Engineering Chemistry Research, 49, 3533-3538.

2. Byrne, G.A., Gardiner, D., Holmes, F.H. 1966. Pyrolysis of Cellulose and Actiuon of Flame Retardants 2. Further Analysis and Identification of Products.. Journal of Applied Chemistry, 16(3), 81-88.

3. Carlson, T.R., Cheng, Y.T., Jae, J., Huber, G.W. 2011. Production of green aromatics and olefins by catalytic fast pyrolysis of wood sawdust. Energy \& Environmental Science, 4(1), 145-161.

4. Case, P.A., Wheeler, M.C., DeSisto, W.J. 2014. Effect of Residence Time and Hot Gas Filtration on the Physical and Chemical Properties of Pyrolysis Oil. Energy \& Fuels.

5. DeSisto, W.J., Hill, N., Beis, S.H., Mukkamala, S., Joseph, J., Baker, C., Ong, T.H., Stemmler, E.A., Wheeler, M.C., Frederick, B.G., van Heiningen, A. 2010. Fast Pyrolysis of Pine Sawdust in a Fluidized-Bed Reactor. Energy \& Fuels, 24, 26422651.

6. Di Blasi, C., Galgano, A., Branca, C. 2009. Influences of the Chemical State of Alkaline Compounds and the Nature of Alkali Metal on Wood Pyrolysis. Industrial \& Engineering Chemistry Research, 48(7), 3359-3369.

7. Diebold, J.P. 2000. A review of the chemical and physical mechanisms of the storage stability of fast pyrolysis bio-oils. National Renewable Energy Laboratory Golden, CO.

8. Hicks, J.C. 2011. Advances in C-O bond transformations in lignin-derived compounds for biofuels production. Journal of Physical Chemistry Letters, 2, 2280-2287.

9. Kakzeski, J., Bruijnincx, P.C., Jongerius, A.L., Weckhuysen, B.M. 2010. The catalytic valorization of lignin for the production of renewable chemicals. Chemical Reviews, 110, 3552-3599.

10. Kaldstrom, M., Kumar, N., Heikkila, T., Tiitta, M., Salmi, T., Murzin, D.Y. 2011. Transformation of levoglucosan over H-MCM-22 zeolite and H-MCM-41 mesoporous molecular sieve catalysts. Biomass \& Bioenergy, 35(5), 1967-1976.

11. Kawamoto, H., Yamamoto, D., Saka, S. 2008. Influence of neutral inorganic chlorides on primary and secondary char formation from cellulose. Journal of Wood Science, 54(3), 242-246.

12. Kuzhiyil, N., Dalluge, D., Bai, X., Kim, K.H., Brown, R.C. 2012. Pyrolytic sugars from cellulosic biomass. ChemSusChem, 5(11), 2228-36.

13. Lin, Y.Y., Zhang, C., Zhang, M.C., Zhang, J.A. 2010. Deoxygenation of Bio-oil during Pyrolysis of Biomass in the Presence of $\mathrm{CaO}$ in a Fluidized-Bed Reactor. Energy \& Fuels, 24, 5686-5695.

14. Marchand-Geneste, N., Carpy, A. 2003. Theoretical study of the thermal degradation pathways of abietane skeleton diterpenoids: aromatization to retene. Journal of Molecular Structure: THEOCHEM 635(1-3), 55-82.

15. Marker, T.L., Felix, L.G., Linck, M.B., Roberts, M.J. 2012. Integrated Hydropyrolysis and Hydroconversion (IH2) for the Direct Production of Gasoline 
and Diesel Fuels or Blending Components from Biomass, Part 1: Proof of Principle Testing. Environmental Progress \& Sustainable Energy, 31(2), 191-199.

16. Mars, P., Scholten, J.J.F., Zwietering, P. 1963. The catalytic decomposition of formic acid. in: Advances in Catalysis and related subjects, Vol. 14, Academic Press.

17. Meesuk, S., Cao, J.P., Sato, K., Ogawa, Y., Takarada, T. 2011. Study of Catalytic Hydropyrolysis of Rice Husk under Nickel-Loaded Brown Coal Char. Energy \& Fuels, 25(11), 5438-5443.

18. Mihalcik, D.J., Mullen, C.A., Boateng, A.A. 2011. Screening acidic zeolites for catalytic fast pyrolysis of biomass and its components. Journal of Analytical and Applied Pyrolysis, 92, 224-232.

19. Mortensen, P.M., Grunwaldt, J.D., Jensen, P.A., Knudsen, K.G., Jensen, A.D. 2011. A review of catalytic upgrading of bio-oil to engine fuels. Applied Catalysis A: General, 407(1-2), 1-19.

20. Mukkamala, S., Wheeler, M.C., van Heiningen, A.R.P., DeSisto, W.J. 2012. FormateAssisted Fast Pyrolysis of Lignin. Energy \& Fuels, 26(2), 1380-1384.

21. Mullen, C.A., Boateng, A.A., Mihalcik, D.J., Goldberg, N.M. 2011. Catalytic Fast Pyrolysis of White Oak Wood in a Bubbling Fluidized Bed. Energy \& Fuels, 25(11), 5444-5451.

22. Patwardhan, P.R., Satrio, J.A., Brown, R.C., Shanks, B.H. 2010. Influence of inorganic salts on the primary pyrolysis products of cellulose. Bioresource Technology, 101(12), 4646-4655.

23. Pütün, E. 2010. Catalytic pyrolysis of biomass: Effects of pyrolysis temperature, sweeping gas flow rate and $\mathrm{MgO}$ catalyst. Energy, 35(7), 2761-2766.

24. Venkatakrishnan, V.K., Degenstein, J.C., Smeltz, A.D., Delgass, W.N., Agrawal, R., Ribeiro, F.H. 2014. High-pressure fast-pyrolysis, fast-hydropyrolysis and catalytic hydrodeoxygenation of cellulose: production of liquid fuel from biomass. Green Chemistry, 16(2), 792-802.

25. Veses, A., Aznar, M., Martinez, I., Martinez, J.D., Lopez, J.M., Navarro, M.V., Callen, M.S., Murillo, R., Garcia, T. 2014. Catalytic pyrolysis of wood biomass in an auger reactor using calcium-based catalysts. Bioresource Technology, 162, 250-258.

26. Wan, H., Chaudhari, R., Subramaniam, B. 2012. Catalytic Hydroprocessing of pCresol: Metal, Solvent and Mass-Transfer Effects. Topics in Catalysis, 55(3-4), 129-139.

27. Wang, Z., Wang, F., Cao, J., Wang, J. 2010. Pyrolysis of pine wood in a slowly heating fixed-bed reactor: Potassium carbonate versus calcium hydroxide as a catalyst. Fuel Processing Technology, 91(8), 942-950.

28. Wildschut, J., Mahfud, F.H., Venderbosch, R.H., Heeres, H.J. 2009. Hydrotreatment of Fast Pyrolysis Oil Using Heterogeneous Noble-Metal Catalysts. Industrial \& Engineering Chemistry Research, 48(23), 10324-10334.

29. Zacher, A.H., Olarte, M.V., Santosa, D.M., Elliott, D.C., Jones, S.B. 2014. A review and perspective of recent bio-oil hydrotreating research. Green Chemistry, 16(2), 491-515.

30. Zhao, C., He, J.Y., Lemonidou, A.A., Li, X.B., Lercher, J.A. 2011. Aqueous-phase hydrodeoxygenation of bio-derived phenols to cycloalkanes. Journal of Catalysis, 280(1), 8-16. 
31. Zhao, C., Kou, Y., Lemonidou, A.A., Li, X.B., Lercher, J.A. 2010.

Hydrodeoxygenation of bio-derived phenols to hydrocarbons using RANEY (R) $\mathrm{Ni}$ and Nafion/SiO2 catalysts. Chemical Communications, 46(3), 412-414. 


\section{Figure Captions}

Figure 1. Thermogravimetric analysis of the solid product was used to calculate the amount of $\mathrm{CO}_{2}$ released during decomposition of calcium carbonate $\left(600-700{ }^{\circ} \mathrm{C}\right)$. This information, together with the known weight of calcium allows for determination of the ratio of oxide:carbonate in the solid product. As expected for calcium formate and calcium carbonate pretreatments, all of the calcium in the char is present as the carbonate. About $70 \%$ of the calcium hydroxide and $65 \%$ of the calcium oxide are converted to calcium carbonate by sequestration of $\mathrm{CO}_{2}$.

Figure 2. Yields of non-condensable gas products from pyrolysis of pine sawdust and pretreated pine sawdust.

Figure 3. (a) Major phenolic products in the oils consist of catechols and phenols. Calcium pretreatment causes an increase in phenol-type compounds and a decrease in catechol-type compounds. (b) Five-membered rings present in the oils include furfural and substituted cyclopentenones. The degree of alkyl substitution increases when calcium pretreatment with formate, carbonate, hydroxide or oxide is employed.

Figures 4. Results of SEC analysis of the various calcium pretreated oils at different stages of aging.

Figure 5. Conceptual flow diagram for production of calcium formate from pyrolysis residue. Char from pyrolysis of calcium formate pretreated biomass can be gasified to produce carbon monoxide, which is then contacted with calcium hydroxide. Calcium hydroxide is regenerated by slaking calcium oxide, which is the resulting product of high temperature oxidation of calcium carbonate. 
Table 1. Mass balances based on grams of reactant/product per 100 gram of pine fed

\begin{tabular}{|c|c|c|c|c|c|c|}
\hline & Pine & $\begin{array}{l}\mathrm{CaSO}_{4} \\
\text { Treated } \\
\text { Pine }\end{array}$ & $\begin{array}{l}\mathrm{Ca}(\mathrm{COOH})_{2} \\
\text { Treated Pine }\end{array}$ & $\begin{array}{l}\mathrm{CaCO}_{3} \\
\text { Treated } \\
\text { Pine }\end{array}$ & $\begin{array}{l}\mathrm{Ca}(\mathrm{OH})_{2} \\
\text { Treated } \\
\text { Pine }\end{array}$ & $\begin{array}{l}\mathrm{CaO} \\
\text { Treated } \\
\text { Pine }\end{array}$ \\
\hline Water & 7 & 15 & 12 & 10 & 18 & 17 \\
\hline Organic product & 21 & 29 & 23 & 12 & 14 & 12 \\
\hline Char product* & 12 & 11 & 36 & 17 & 21 & 13 \\
\hline Gas product & 58 & 48 & 61 & 51 & 33 & 24 \\
\hline $\mathrm{CaSO}_{4}$ in solid product** & 0 & 146 & 0 & 0 & 0 & 0 \\
\hline $\mathrm{CaCO}_{3}$ in solid product** & 0 & 0 & 107 & 107 & 74 & 70 \\
\hline $\mathrm{CaO}$ in solid product** & 0 & 0 & 0 & 0 & 18 & 21 \\
\hline $\operatorname{Sum}^{\dagger}$ & 98 & 249 & 239 & 197 & 178 & 157 \\
\hline Mass Balance Closure & $98 \%$ & $101 \%$ & $99 \%$ & $95 \%$ & $99 \%$ & $98 \%$ \\
\hline
\end{tabular}

* On a calcium-free basis

** Refer to Figure 1 for more information about calcium compounds remaining in char

$\dagger$ For the pretreated pine cases, the sum is greater than 100 because it is calculated on a pine basis but includes the mass of the pretreatment compound. 
Table 2. Properties of liquid products with and without pretreatment

\begin{tabular}{|l|l|l|l|l|l|l|l|}
\hline & $\begin{array}{l}\text { Pine } \\
\text { Feed }\end{array}$ & $\begin{array}{l}\text { Pine } \\
\text { Oil }\end{array}$ & $\begin{array}{l}\mathrm{CaSO}_{4} \\
\text { Treated } \\
\text { Pine Oil }\end{array}$ & $\begin{array}{l}\mathrm{Ca}(\mathrm{COOH})_{2} \\
\text { Treated } \\
\text { Pine Oil }\end{array}$ & $\begin{array}{l}\mathrm{CaCO}_{3} \\
\text { Treated } \\
\text { Pine Oil }\end{array}$ & $\begin{array}{l}\mathrm{Ca}(\mathrm{OH})_{2} \\
\text { Treated } \\
\text { Pine Oil }\end{array}$ & $\begin{array}{l}\mathrm{CaO} \\
\text { Treated } \\
\text { Pine Oil }\end{array}$ \\
\hline \% Carbon (dry basis) & 45.1 & 67.8 & 65.7 & 76.6 & 78.7 & 81.6 & 82.9 \\
\hline Carbon Yield & - & 32 & 42 & 39 & 21 & 25 & 22 \\
\hline \% Hydrogen (dry basis) & 6.80 & 6.50 & 6.33 & 7.30 & 6.99 & 7.26 & 7.16 \\
\hline \% Oxygen (by difference) & 48.1 & 25.7 & 27.9 & 16.3 & 14.3 & 11.1 & 9.94 \\
\hline O:C (oil) & 0.80 & 0.28 & 0.32 & 0.16 & 0.14 & 0.10 & 0.09 \\
\hline H:C (oil) & 1.80 & 1.15 & 1.16 & 1.15 & 1.07 & 1.07 & 1.03 \\
\hline
\end{tabular}


Table 3. Most abundant compounds quantified by GC-MS

\begin{tabular}{|c|c|c|c|c|c|c|c|}
\hline \multirow{2}{*}{ Retention Time } & \multirow{2}{*}{ Compound Identification } & \multicolumn{6}{|c|}{ Concentration ( $\mu \mathrm{g} / \mathrm{g})$} \\
\hline & & Pine & $\mathrm{Ca}(\mathrm{SO} 4)$ & $\mathrm{Ca}(\mathrm{COOH}) 2$ & $\mathrm{CaCO} 3$ & $\mathrm{Ca}(\mathrm{OH}) 2$ & $\mathrm{CaO}$ \\
\hline 6.9 & Cyclopentenone & - & - & 5,268 & 9,766 & 8,562 & 4,191 \\
\hline 7.4 & Furfural & 2,207 & 4,816 & - & - & - & - \\
\hline 10.4 & 2-methyl-2-cyclopenten-1-one & 1,476 & 1,193 & 6,492 & 8,356 & 11,627 & 12,951 \\
\hline 13.5 & 3-methyl-2-cyclopenten-1-one & 2,790 & 2,804 & 6,143 & 10,326 & 11,207 & 11,659 \\
\hline 15.3 & Ethylene glycol & 4,943 & 4,618 & 3,391 & 1,018 & 1,091 & 963 \\
\hline 18.1 & 2,3-Dimethyl-2-cyclopenten-1-one & - & - & 4,280 & 4,511 & 6,653 & 10,934 \\
\hline 19.2 & Phenol & 6,105 & 6,798 & 8,668 & 16,920 & 21,126 & 32,610 \\
\hline 19.9 & Acetophenone & 161 & & 200 & 136 & 820 & 1,485 \\
\hline 24.4 & o-cresol & 2,797 & 2,801 & 6,160 & 9,065 & 10,471 & 16,291 \\
\hline 25.2 & m-cresol & 7,610 & 7,886 & 7,618 & 14,961 & 15,996 & 23,656 \\
\hline 25.9 & p-cresol & 3,114 & 2,864 & 5,961 & 9,387 & 10,426 & 16,487 \\
\hline 27.5 & Napthalene & - & - & 894 & 994 & 1,748 & 3,143 \\
\hline 30.1 & 2,5-dimethylphenol & 493 & 378 & 1,932 & 3,150 & 3,371 & 5,301 \\
\hline 31.0 & 2,4-dimethylphenol & 2,414 & 1,711 & 5,840 & 10,239 & 10,773 & 14,867 \\
\hline 31.6 & 2,6-xylenol & - & - & 1,674 & 1,027 & 1,408 & 1,709 \\
\hline 32.0 & 4-ethylphenol & 2,359 & 1,481 & 3,564 & 7,601 & 8,658 & 11,705 \\
\hline 33.5 & 3,4-dimethylphenol & - & - & 1,197 & 2,555 & 2,092 & 4,557 \\
\hline 36.7 & Hydroxyacetophenone & 740 & 317 & 946 & 1,596 & 1,823 & 3,626 \\
\hline 37.4 & Catechol & 38,441 & 33,371 & 17,306 & 9,323 & 7,789 & 1,888 \\
\hline 37.7 & $2,3,5$ trimethylphenol & - & - & 3,170 & 3,455 & 3,165 & 4,748 \\
\hline 42.3 & 4-methylcatechol & 23,383 & 23,023 & 14,920 & 9,248 & 7,723 & 1,485 \\
\hline 42.9 & 3-methylcatechol & 7,181 & 6,913 & 7,899 & 7,001 & 6,490 & 870 \\
\hline 47.5 & 4-ethylcatechol & 23,998 & 19,623 & 14,623 & 5,391 & 5,389 & 1,453 \\
\hline 52.4 & 1-hydroxynapthalene & 912 & 457 & 223 & 2,805 & 3,355 & 6,437 \\
\hline 53.4 & Benzoic Acid & 3,242 & 2,266 & 3,042 & 1,024 & 775 & - \\
\hline 53.9 & 1,2,3-trihydroxybenzene & 597 & 274 & 263 & 229 & - & - \\
\hline 54.1 & 2-hydroxynapthalene & 891 & 419 & 1,952 & 4,372 & 5,443 & 9,740 \\
\hline 58.6 & $1,2,4$ trihydroxybenzene & 946 & 673 & 427 & 471 & - & - \\
\hline 66.6 & Levoglucosan & 33,535 & 7,159 & 5,092 & 1,160 & 496 & 408 \\
\hline 77.3 & Retene & - & 2,595 & 4,354 & 10,777 & 12,623 & 24,271 \\
\hline 79.2 & Dehydroabietic acid & 6,489 & 1,215 & 1,024 & - & - & - \\
\hline 79.8 & Dihydroxycoumarin & - & - & 2,712 & 7,473 & 13,599 & 15,774 \\
\hline & Percent of Oil Identified & 0.18 & 0.14 & 0.14 & 0.17 & 0.18 & 0.23 \\
\hline
\end{tabular}


Figure 1.

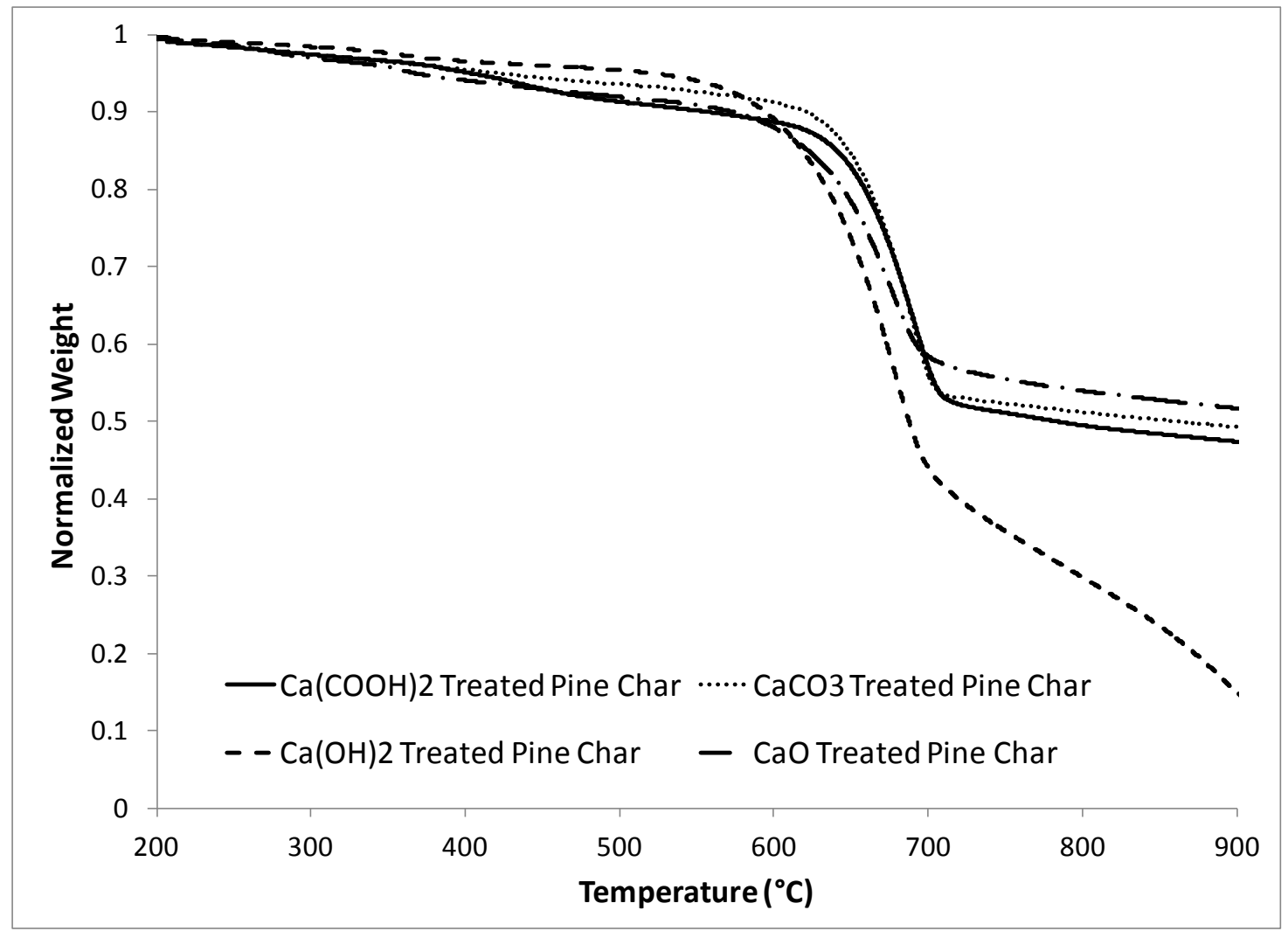


Figure 2.

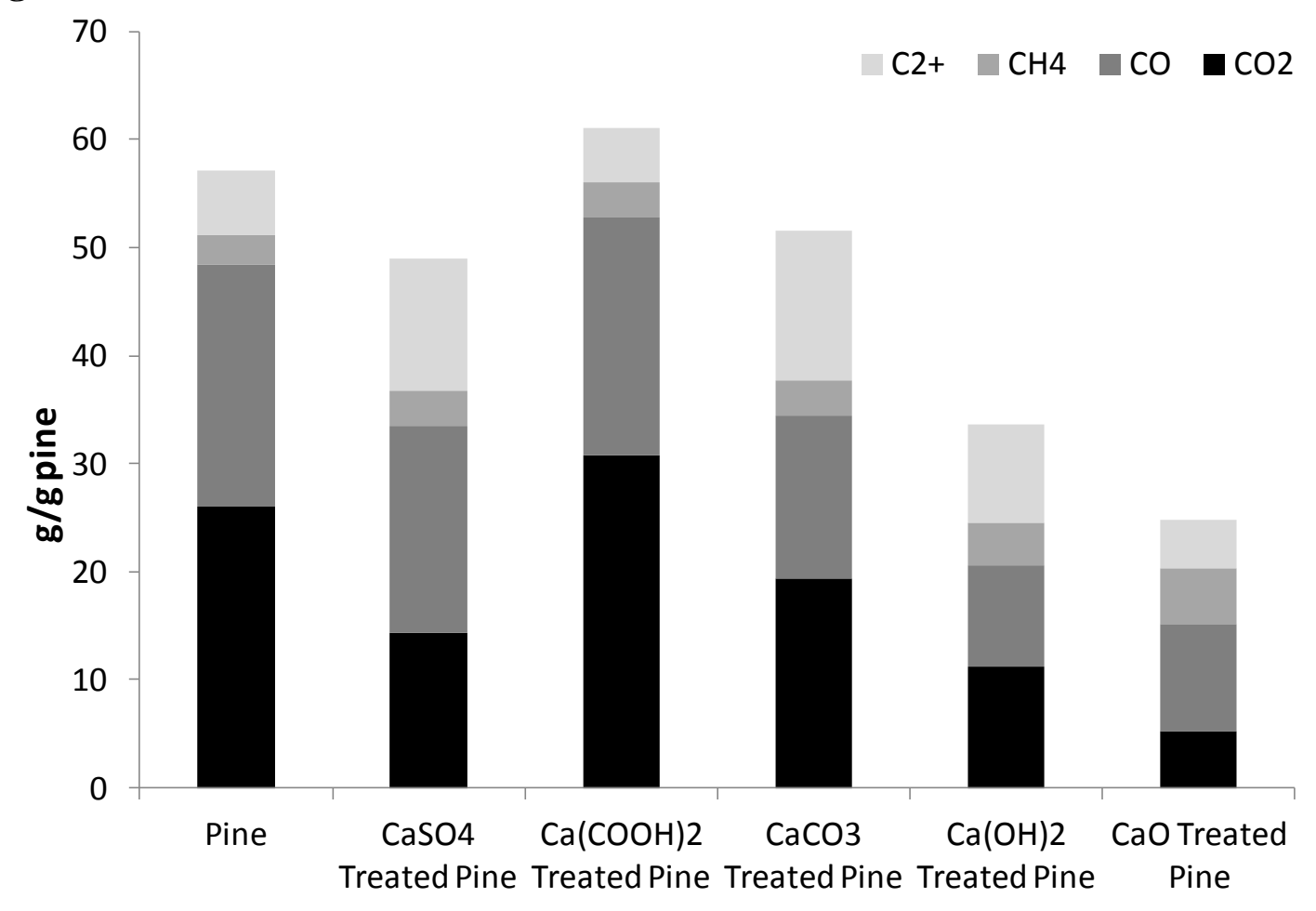


Figure 3.

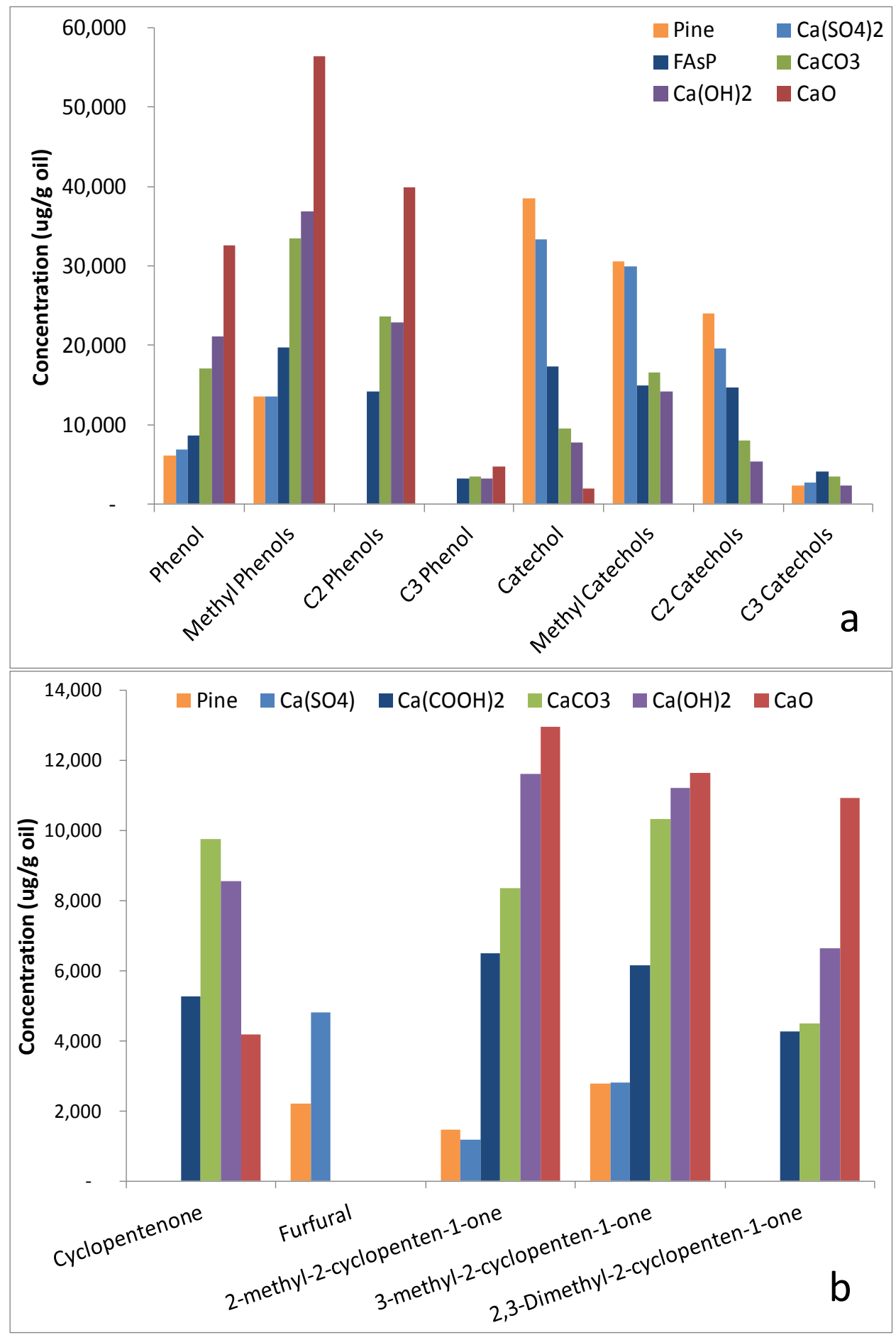




\section{Figure 4}
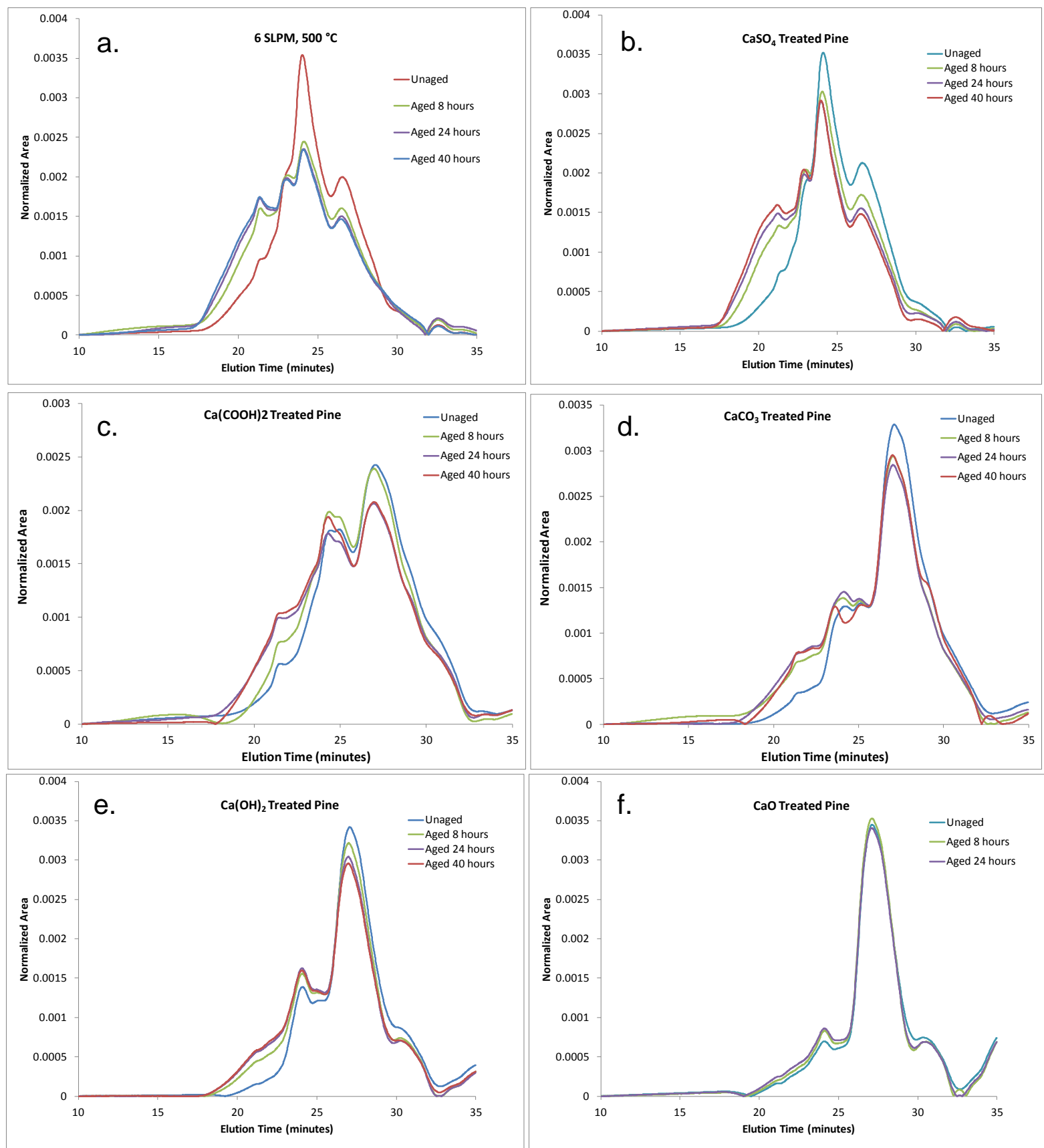
Figure 5.

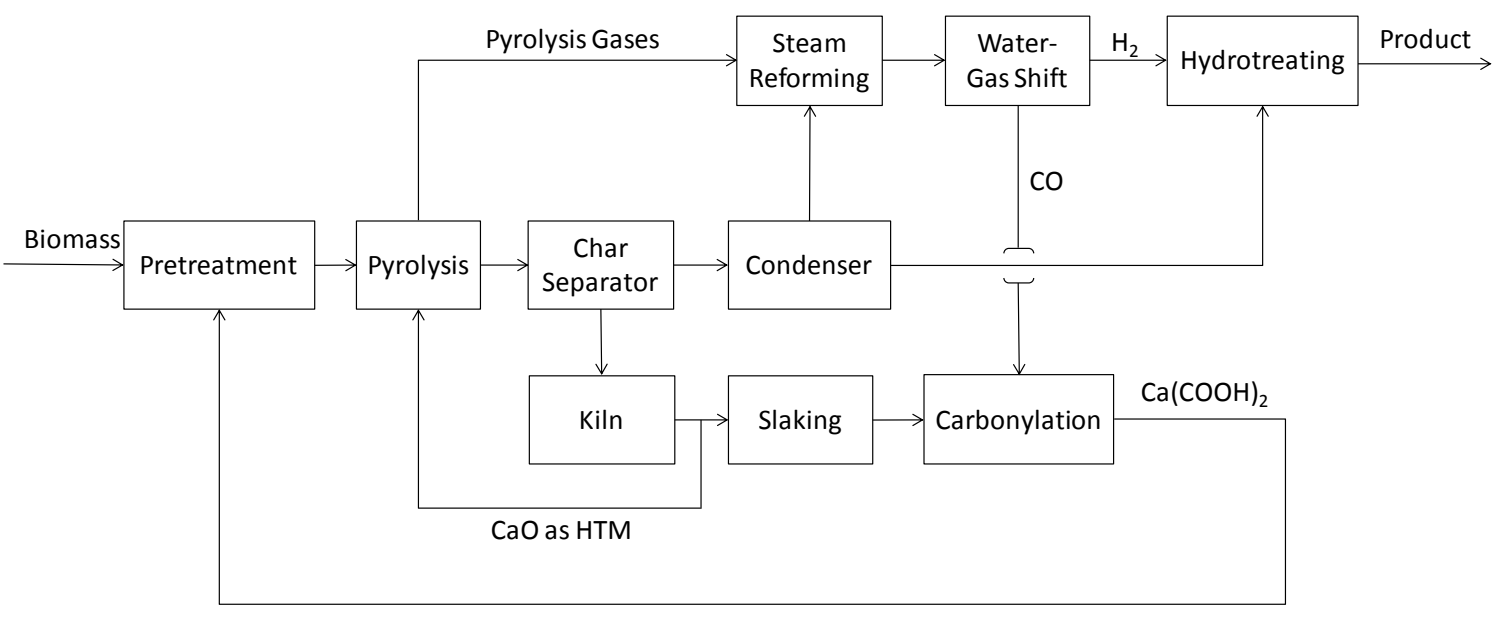

